\title{
REALIZAÇÃO DE PROCESSOS VERBAIS EM TEXTOS CIENTÍFICOS DA ÁREA DE ENGENHARIA CIVIL
}

\author{
(Realization of verbal processes in scientific \\ texts in the field of civil engineering)
}

Cristiane FUZER

(UFSM)

Resumo: O presente trabalho, vinculado ao projeto $S A L$, apresenta um estudo da realização de processos verbais em língua portuguesa do Brasil em textos da área de Engenharia Civil. O objetivo é analisar quais formas linguísticas realizam processos verbais, com que frequência são usados e que significados produzem em textos científicos dessa área. O corpus de análise constitui-se de 51 textos que compõem os volumes 1 e 2 do livro "Concreto: ciência e tecnologia", publicada pelo IBRACON (Instituto Brasileiro do Concreto). Para a compilação do corpus, seguiram-se princípios da Linguística de Corpus (Sardinba, 2004; Almeida E Correia, 2008). A identificação das formas linguísticas e o tratamento quantitativo dos dados foram realizados com auxilio das ferramentas WordListe Concord do WordSmith Tools (SCOTT, 2008). A análise das formas linguísticas foi realizada com base nos critérios da Gramática Sistêmico-Funcional (Halliday E Mattbiessen, 2004) para descrição e classificação de processos verbais. Os resultados apontam que os verbos mais frequentes do corpus, recomendar e especificar, funcionam como processos de semiose do tipo comando e podem ser consideradas características do discurso científico na área de Engenharia Civil. Formas linguísticas em terceira pessoa do presente e no particípio servem como recurso de impessoalização no discurso científico.

Palavras-chave: Projeto SAL, processos verbais, discurso científico.

Abstract: This paper, linked to the SAL project, presents a study on the realization of verbal processes in Brazilian Portuguese in Civil Engineering texts. Its aim is to analyse the linguistic forms that realize verbal processes, how often they are used and what meanings they produce in texts in that field. The corpus consists of the 51 texts in the 2 volumes of the book Concreto: ciência e tecnologia, published by IBRACON (InstitutoBrasileiro do Concreto). To compile the corpus we followed the principles of Corpus Linguistics (Sardinha, 2004; Almeida E Correia, 2008). The identification of the linguistic forms and the quantitative treatment of the data were done with the help of WordList and Concord from WordSmith Tools (Scott, 2008). The analysis of the linguistic forms was based on the criteria of Systemic Functional Grammar (Halliday E Matthiessen, 2004) to describe

D.E.L.T.A., 28:Especial, 2012 (473-494) 
and classify verbal processes. The results show that the most frequent verbs in the corpus, recommend and specify, work as processes of semiosis of the group command and may be considered characteristics of the scientific discourse in Civil Engineering. Linguistic forms in the third person in the present and in the participle work as a resource for impersonality in the scientific discourse.

Key-words: SAL Project, verbal processes, scientific discourse.

\section{INTRODUÇÃO}

O presente trabalho tem como objetivo apresentar um estudo da realização de processos verbais em língua portuguesa do Brasil usados em textos de uma ciência específica: a subárea Engenharia Civil, que integra a grande área Engenharias(na classificação do CNPq - Conselho Nacional de Pesquisa). $\mathrm{O}$ trabalho visa contribuir para o mapeamento do uso de processos verbais em português do Brasil,em discursos científicos, conforme prevê o projeto SAL(Sistêmica Através de Línguas), coordenado por Matthiessen, Teruya e Barbara (2008).

Os textos selecionados para análise, produzidos por pesquisadores e profissionais especializados em engenharia da construção, compõem o livro intitulado Concreto: ciência e tecnologia, publicado em 2011 pelo IBRACON (Instituto Brasileiro do Concreto). Segundo seus editores, o livro é destinado aos associados, estudantes e profissionais da área da Construção Civil e, em especial, do Concreto Estrutural, "com o intuito de apresentar à comunidade técnico-científica brasileira os últimos avanços ocorridos nos últimos seis anos em pesquisas na área dos materiais cimentícios e a sua aplicação tecnológica nas obras de construção civil" (Isaia, 2011:2).

Inseridas nesse contexto específico, esses textos são analisados neste trabalho com o objetivo de verificar quais formas linguísticas realizam processos verbais, com que frequência são usados e que significados produzem nos textos científicos selecionados para compor um compêndio que contempla avanços recentes na área da Engenharia Civil.

Para isso, após um levantamento, na seção 2, de estudos prévios sobre processos verbais na perspectiva sistêmico-funcional, são revisados, na seção 3, pressupostos teóricos da Gramática Sistêmico-Funcional, de Halliday \& Matthiessen (2004). As diretrizes metodológicas para a constituição do corpus, conforme princípios da Linguística de Corpus (Sardinha, 2004; 
Almeida \& Correia, 2008) e os passos da análise estão descritas na seção 4. A descrição e análise dos dados são apresentadas na seção 5 , seguida de algumas considerações finais, na seção 6 , sobre os processos verbais que representam o dizer de pesquisadores e profissionais da área de Engenharia Civil no contexto especificado.

\section{ESTUDOS PRÉVIOS SOBRE PROCESSOS VERBAIS NA PERSPECTIVA SISTÊMICO-FUNCIONAL}

Trabalhos de análise da língua portuguesa do Brasil sob a perspectiva sistêmico-funcional têm desvelado padrões de uso de recursos léxicogramaticais em diferentes contextos, tais como:escolar, jurídico, midiático, acadêmico. Resultados relatados nesses trabalhos de que faz parte o estudo de processos verbais fornecem um panorama do que se conseguiu mapear sobre o funcionamento do português do Brasil em relação ao uso desse recurso léxico-gramatical.

No contexto escolar, Ramos (2010) identificou processos verbais nominalizados em 50 textos dissertativo-argumentativos produzidos por alunos do ensino médio e concluiu que, em relação à estrutura temática, as nominalizações estabelecem relações lógicas e favorecem o fluxo das informações nos textos.

No contexto jurídico, o estudo dos gêneros denúncia, alegações finais e sentença condenatória, que constituem os autos de um processo penal, Fuzer \& Barros (2010) encontraram processos verbais específicos da prática jurídica, como "denunciar", "pronunciar", "interrogar" e "requerer", desempenhando ações em relação a um Alvo, razão pela qual foram classificados como processos verbais de atividade.

No contexto midiático, três trabalhos vinculados ao projeto SAL atestam a presença marcante de processo verbal de semiose neutro ${ }^{1}$ em textos da esfera jornalística. Pesquisando representações sobre a credibilidade do judiciário pela mídia, Kurtz (2011) encontrou, em 87 notícias políticas, a predominância do verbo "dizer" projetando Citações e Relatos na circulação de representações.O verbo "dizer" também é o mais frequente, seguido de

1. Sobre essa categoria, ver seção 3. 
“afirmar”, em um corpus de 656 notícias sobre assuntos diversos, veiculadas na Folha de São Paulo e na BBC em português, analisado por Cabral \& Barbara (no prelo). Segundo as autoras, a neutralidade expressa por "dizer" e a semiose de indicação expressa por "afirmar" reforçam a busca, no discurso das notícias, por ausência de interferência valorativa.Resultado semelhante foi encontrado por Silva (2012) na análise de notícias, reportagens e artigos de opinião, veiculados na mídia eletrônica, totalizando 19 textos, sobre homossexuais idosos. Os verbos "dizer" e "afirmar" foram os mais utilizados para introduzir vozes externas.

No contexto acadêmico, o verbo "dizer", prototípico da declaração, também se mostrou mais frequente em 43 artigos científicos da área de Linguística Aplicada,analisados por Vivan (2010). Resultado diferente, porém, foi encontrado por Barbara e Macêdo (2011), que levantaram padrões de realização de orações verbais em 1225 artigos científicos de diversas subáreas das grandes áreas da ciência, publicados em revistas da base de dados Scielo Brasil.Nesses artigos, os verbos "sugerir" e "afirmar" foram os mais frequentes. A alta frequência do verbo "afirmar", em especial, pode ser, segundo as autoras, resultado de uma mudança linguística no português do Brasil, já que o posicionamento categórico indicado por esse verbo "não é característico da ciência contemporânea" (BArabara \& Macêdo, 2004:230).

A fim de contribuir para a ampliação dos estudos sobre processos verbais no contexto científico, o presente trabalho delimita-se a uma área específica do conhecimento - a Engenharia Civil. Dessa forma, pretende-se fornecer subsídios para a identificação de aspectos linguísticos que possam ser considerados características dessa ciência, conforme prevê o projeto SAL.

\section{FundamentaÇão TEÓRICA NA PERSPECTIVA SISTÊMICO-FUNCIONAL}

O estudo da gramática na teoria sistêmico-funcional é realizado em articulação com o que ocorre fora da linguagem, com os acontecimentos e as condições de um grupo ou comunidade (contexto de cultura) e com os processos sociais em que estão inseridos (contexto de situação).Nessa perspectiva, a gramática está construída sobre um sistema de escolhas possíveis a um falante/ouvinte no momento da comunicação. Por isso, "diferentes tipos de texto (registros) favorecem diferentes tipos de expansão e tam- 
bém diferentes tipos de estrutura gramatical” (Halliday \& Matthiessen, 2004:594).

Na teoria sistêmico-funcional, a linguagem desempenha duas funções básicas:a representação de experiências do mundo exterior ou interior (metafunção ideacional ${ }^{2}$ ) e a negociação de significados (metafunção interpessoal). A organização dos significados experienciais e interpessoais é um terceiro tipo de função da linguagem (metafunção textual). Cada uma dessas metafunções, que constituem o estrato semântico da linguagem, realiza-se por meio de um sistema léxico-gramatical: transitividade, modo e estrutura temática.

O sistema de transitividade "constrói o mundo de experiências gerenciável pelos tipos de processos" (Halliday \& Matthiessen, 2004:170), formando uma "figura". Figuras são constituídas de processo e participantes (quem faz o quê) e, eventualmente, de circunstâncias associadas ao processo (onde, quando, como, por que, para que, etc.).

Os processos materiais, mentais e relacionais são os tipos básicos. Da relação entre eles surgem os verbais, existenciais e comportamentais, que, apesar de apresentarem algumas características comuns, têm suas especificidades sintáticas e semânticas.

Para Halliday \& Matthiessen (2004:181), a "transitividade é um sistema da oração que afeta não apenas o verbo que serve como processo, mas também os participantes e as circunstâncias". Por isso, a oração é classificada conforme o tipo de processo, realizado por um grupo verbal. Também dependendo do tipo de processo, os participantes, realizados tipicamente por grupos nominais, recebem diferentes denominações. Apresentam-se aqui informações sobre as orações verbais, que são o foco deste trabalho.

Em orações verbais, o processo se realiza por um verbo de dizer, que pode apresentar características de outros processos: tempo semelhante ao dos processos materiais (presente no presente) ou relacionais (presente simples), bem como capacidade de projeção como a dos processos mentais (Halliday \& Matthiessen, 2004: 255). O Quadro 1 apresenta os tipos de processos verbais e exemplos de verbos que podem realizá-los no discurso.

2. A metafunção ideacional compõe-se de dois tipos: experiencial e lógica, cujas unidades deanálise são, respectivamente, a oração e o complexo oracional. 
Quadro 1: Exemplos de verbos que realizam processos em orações verbais

\begin{tabular}{|l|l|l|}
\hline \multicolumn{2}{|c|}{ Tipos } & Exemplos de verbos \\
\hline \multirow{3}{*}{ Atividade } & Alvo & $\begin{array}{l}\text { elogiar, insultar, abusar, caluniar, lisonjear, culpar, criticar, } \\
\text { repreender, acusar* }\end{array}$ \\
\cline { 2 - 4 } & Fala & falar, conversar \\
\hline \multirow{4}{*}{ Semiose } & Neutro & dizer, falar \\
\cline { 2 - 4 } & Indicação & $\begin{array}{l}\text { contar (a alguém que), relatar, anunciar, expor, explicar, provar, ar- } \\
\text { gumentar, convencer (de que), persuadir (de que), prometer (que), } \\
\text { perguntar (a alguém se), questionar, inquirir (se) }\end{array}$ \\
\cline { 2 - 3 } & Comando & $\begin{array}{l}\text { dizer (a alguém que faça), solicitar/pedir (a alguém que faça), } \\
\text { ordenar, mandar, requerer, prometer, ameaçar, persuadir (alguém } \\
\text { a fazer), convencer (alguém a fazer), suplicar, implorar, rogar. }\end{array}$ \\
\hline
\end{tabular}

Adaptados de Halliday \& Matthiessen, 2004:255.

Nos processos verbais podem estar envolvidos os seguintes participantes: Dizente, Receptor, Alvo e Verbiagem.

O Dizente é realizado por grupo nominal que denota um falante consciente ou outro recurso simbólico no lugar de um falante humano.O Receptor é aquele a quem é dirigido o conteúdo do dizer e é tipicamente realizado por um grupo nominal que pode vir acompanhado de uma preposição.

O Alvo ocorre somente num subtipo de oração verbal de atividade (targeting) e constrói a entidade que é atingida pelo processo de dizer. $\mathrm{O}$ Dizente age verbalmente sobre esse participante que geralmente se realiza por um grupo nominal.

A Verbiagem, também realizado por um grupo nominal, representa o conteúdo do que é dito,um resumo do que foi dito ou um rótulo para descrever a própria língua ${ }^{3}$. Alternativamente, o conteúdo do dizer pode

*. Os verbos denunciar, pronunciar e interrogar também podem funcionar como processos verbais relacionados a um Alvo em determinados contextos - por exemplo, no contexto jurídico, como em "O Ministério Público denunciouFulana pela prática do crime de homicídio duplamente qualificado" (FUZER \& BARROS, 2010: 90).

3. Exemplos desses tipos de Verbiagem estão sublinhados em: "dizer uma palavra", "fazer uma pergunta" e "falar português". 
vir realizado na forma de outra oração (projetada), que pode se apresentar sob dois tipos:

- Citação, tipicamente entre aspas, precedida ou não de conjunções integrantes "que" ou "se", sinais de pontuação (dois-pontos, travessão, vírgula);

- Relato, tipicamente precedida de conjunções integrantes "que" ou "se", sem a presença de aspas.

O uso de Citação implica a reprodução do conteúdo e da forma do dizer original, sem alterações ${ }^{4}$, ao passo que o uso de Relato permite paráfrases com mudanças em termos de anáfora, modo verbal (Barbara \& Macêdo, 2011), o que pode implicar ou não sutis alterações em relação ao dizer da fonte.

Halliday \& Matthiessen (2004:252-3) mencionam alguns usos discursivos de orações verbais, tais como:

- construção de passagens dialógicas em narrativas escritas e conversações;

- atribuição de informações às fontes (autoridades, especialistas e testemunhas) em notícias;

- citações e relatos de pesquisadores e indicação da posição do escritor em discursos acadêmicos.

As representações das diversas experiências construídas na e pela linguagem podem ser trocadas entre as pessoas também por meio da linguagem, a qual passa a desempenhar a metafunção interpessoal. Essa metafunção é realizada léxico-gramaticalmente pelo sistema de MODO, que "é o recurso gramatical para se realizarem movimentos interativos no diálogo" (Martin et al., 1997, p. 58). Segundo Halliday e Matthiessen (2004), a linguagem, nos eventos comunicativos, possibilita "dar" e "solicitar" informações e/ou bens e serviços. Quando é dada informação, tem-se a declaração, e quando são dados bens e serviços, faz-se uma oferta. Por outro lado, quando é

4. Não há alterações na oração citada, geralmente colocada entre aspas ou antecedida de travessão. Entretanto, numa perspectiva bakthiniana, as condições discursivas em que for realizada a colagem de uma Citação ou mesmo o co-texto (palavras ou enunciados no entorno) podem interferir, de alguma maneira, na sua significação. 
solicitada uma informação, faz-se uma pergunta, e quando são solicitados bens e serviços, faz-se um comando. De acordo com Halliday e Matthiessen (2004), as trocas de informações são denominadas "proposições", e as trocas de bens e serviços, "propostas".

A organização dos significados experienciais e interpessoais dá-se por meio da estrutura temática, que envolve as funções léxico-gramaticais Tema e Rema, responsáveis pela progressão temática do texto. Em cada oração, o Tema, primeiro elemento com função experiencial, constitui o ponto de partida da mensagem e indica a progressão de uma informação geral para uma particular, ou vice-versa.

Como o foco deste trabalho são formas linguísticas que realizam processos verbais, categorias do sistema de Modo, especialmente proposição e proposta, e da estrutura temática, quando necessário, serão consideradas na análise. Com base nesses pressupostos, são identificados e analisados processos verbais presentes nos textos que constituem o corpus desta pesquisa, cujas diretrizes metodológicas estão apresentadas a seguir.

\section{Metodologia}

Os dados que constituem o corpus desta pesquisa foram extraídos dos 51 capítulos que compõem os volumes 1 e 2 do livro "Concreto: ciência e tecnologia”, editado por Isaia (2011), em língua portuguesa do Brasil. A obra foi publicada pelo IBRACON (Instituto Brasileiro do Concreto), uma organização técnico-científica que tem o objetivo de

proporcionar aos profissionais e intervenientes do setor de concreto e construção civil,
nas áreas de materiais, tecnologia, projeto, gestão, controle, arquitetura, estruturas
e construções conhecimentos [...], valorização e incentivos às investigações e pesqui-
sas científicas e tecnológicas e sua respectiva divulgação (IBRACON, 2012, online).

Em vista desse contexto, é conveniente acrescentar que esse instituto já reuniu centenas de trabalhos na área em outros três livros anteriormente publicados, envolvendo profissionais e pesquisadores de diferentes instituições, associações e empresas. Segundo o Diretor Presidente do IBRACON, Paulo Helene, no Prefácio de um desses livros, os autores convidados a participar das obras são "selecionados pela sua reconhecida capacidade 
técnica e científica em suas respectivas áreas de atuação. Possuem vivência e experiência dentro de cada tópico abordado" (Isaia, 2007: XI). Mediante esses dados, os textos que constituem este trabalho podem ser considerados representativos do registro científico da área de Engenharia no Brasil.

Para a compilação do corpus inicial que possibilitasse responder às questões levantadas para esta pesquisa, seguiram-se princípios da Linguística de Corpus sistematizados por Sardinha (2004) e Almeida \& Correia (2008). Para a delimitação da área de Engenharia Civil, quatro fatores foram considerados.

Um dos fatores é a relevância dessa área específica do ponto de vista econômico, social, científico e tecnológico para o Brasil, que vem passando por expressivo crescimento no setor imobiliário incentivado por políticas públicas de habitação - realidade que demanda a realização e divulgação de novas pesquisas sobre infraestrutura adequada para as populações humanas.

Outro fator é a facilidade de obtenção dos textos já em formato digital, disponibilizados em arquivos .pdf pelo conselho editorial do IBRACON. Esses arquivos foram convertidos manualmente para o formato .txt. Para a limpeza do corpus, foram excluídos imagens, gráficos, tabelas, quadros e marcas da diagramação (como nomes dos autores e título do livro no cabeçalho e rodapé), para que pudessem ser processados no software WordSmith Tools5.0 (Scott, 2008).

O terceiro fator considerado é a diversidade de autores. Na produção dos textos que constituem o corpus estão envolvidos 70 profissionais, a maioria Doutores em Engenharia (Quadro 2), muitos deles pesquisadores do $\mathrm{CNPq}$ (Conselho Nacional de Pesquisa).

Quadro 2: Titulação dos autores dos textos (conforme informações disponíveis no Curriculum Lattes de cada autor)

\begin{tabular}{|c|r|}
\hline Titulação na área & Quantidade \\
\hline Doutores & 54 \\
\hline Mestres & 9 \\
\hline Graduados & 7 \\
\hline Total & 70 \\
\hline
\end{tabular}


Os locais de trabalho dos autores dos textos também foram levantados (Quadro 3), de modo a conhecer-se a população da qual a amostragem provém (Sardinha, 2004). A maioria dos autores (49) atua em instituições de ensino superior. Outros tantos (21) trabalham para empresas de consultoria em engenharia e de construção; destes quatro também atuam em universidades. Outros autores (4) trabalham para associações.

Quadro 3: Instituições a que os autores estão vinculados

\begin{tabular}{|l|r|}
\hline Local de trabalho dos autores & Quantidade \\
\hline Universidades & \\
USP, PUC, Unicamp, UFSM, UFSC, UFRGS, UFU, UFES, UFG, Unisinos, & \\
Ulbra, Mackenzie... & \\
\hline Empresas Consult. Constr. & \\
Ycon, Tecnum, WRGrace, PhD, Odebrecht, Zamarion e Mile, Eletrobras & \\
Furnas... & \\
\hline $\begin{array}{l}\text { Associações } \\
\text { ABNT (Associação Brasileira de Normas Técnicas), ABCP (Associação } \\
\text { Brasileira de Cimento Portland), ABCIC (Associação Brasileira da }\end{array}$ & \\
Construção Industrializada de Concreto) & \\
\hline
\end{tabular}

Essas condições de autoria evidenciam graus de especialização, bem como experiência teórica e prática no tratamento dos assuntos da área e, principalmente, de elaboração da escrita em termos de registro científico. Por esse critério, tem-se diminuído o risco de escolhas linguísticas serem "apenas um traço estilístico dos autores selecionados" (Almeida \& Correia, 2008: 81). Assim, o caráter probabilístico da linguagem pode ser mais bem observado em termos de recorrências na área de Engenharia Civil em contexto de divulgação científica, havendo a possibilidade de estabelecer, segundo Sardinha (2004), relação entre traços mais comuns e menos comuns nesse contexto.

A diversidade de autores está relacionada, no caso deste estudo, ao quarto fator considerado na compilação do corpus: a representatividade. Por ser um corpus de amostragem e de conteúdo especializado (conforme classificação dada por Sardinha, 2004), a pluralidade de autoria favorece a identificação de um ou mais padrões de uso de orações verbais como 
traço(s) característico(s) da linguagem escrita usada por experts em Engenharia Civil.

A representatividade também está associada à extensão do corpus que, no caso deste estudo, pode ser classificado como médio, segundo parâmetros propostos por Sardinha (2004). O Quadro 4 expõe informações sobre a extensão do corpus para este trabalho.

Quadro 4: Informação estatística do corpus

\begin{tabular}{|l|r|}
\hline Textos & 51 \\
\hline Types (palavras distintas) & 26.071 \\
\hline Tokens (ocorrências) & 59.918 \\
\hline Total de palavras & 644.189 \\
\hline
\end{tabular}

Para a descrição e análise do uso de processos verbais nesse corpus, foram seguidos estes passos:

- obtenção de uma lista de palavras por meio da ferramenta WordList do programa WordSmith Tools 5.0, para localização de formas linguísticas com potencial para desempenhar a função de processos verbais, com base nos critérios descritos na Gramática Sistêmico-Funcional de Halliday \& Matthiessen (2004);

- exame das concordâncias das formas linguísticas nos tempos e modos com que se apresentaram no corpus, a fim de verificar as ocorrências no seu co-texto para confirmação (ou não) da classificação inicial, com base nos critérios propostos pela Gramática Sistêmico-Funcional (Halliday \& Matthiessen, 2004);

- quantificação das ocorrências de processos verbais resultantes desse exame e análise dos processos mais frequentes para análise;

- identificação de padrões que possam sinalizar características da escrita científica na área de Engenharia Civil em relação a esses processos. 


\section{Descrição e ANÁlise dos Resultados}

Para conferir a classificação das formas linguísticas com potencial para desempenhar a função de processo verbal no corpus, foi utilizado o princípio da co-ocorrência, segundo o qual os itens devem estar na presença de outros para serem significativos, já que um item isolado é pouco informativo (SARDINHA, 2004) e pode dar margem a mais de uma interpretação, haja vista a polissemia inerente às palavras e os diferentes co-textos (palavras no entorno) e contextos (de situação e cultura) em que podem ocorrer. Assim, uma mesma forma linguística pode realizar diferentes tipos de processos dependendo dos itens com que se relacionam na oração. Os excertos a seguir exemplificam esse caso.

(1) Semelhante à norma brasileira, a ASTM C618 (2008a) estabelece uma quantidade mínima de $70 \%$ de $(\mathrm{SiO} 2+\mathrm{Al} 2 \mathrm{O} 3+\mathrm{Fe} 2 \mathrm{O} 3)(\ldots)$. (File 8)

(2) A ABNT NBR 8953:2009 estabelece que os concretos estruturais devem ser classificados em dois grupos(...). (File 17)

(3) (...) Para espécies químicas pouco solúveis estabelece-se um equilíbrio entre o sólido e a solução. (File 11)

Em (1), a relação do verbo estabelece com um grupo nominal que tem potencial para desempenhar a função de Dizente (representando metonimicamente por um documento institucional) e com outro grupo nominal com função de Verbiagem permite a identificação do processo verbal.

De maneira semelhante, em (2), o verbo co-ocorre com um grupo nominal que funciona como Dizente (novamente um documento institucional) e com uma oração projetada com função de Relato, o que também possibilita a identificação do processo verbal.

Em (3), por outro lado, não há grupo nominal com potencial para desempenhar a função de Dizente. O grupo nominal que co-ocorre com o verbo funciona como Ator do processo estabelecer, que, no contexto, tem significado semelhante a "ocorrer" ou "acontecer". Orações como essa que não atendem aos critérios de classificação dos processos verbais segundo a teoria sistêmico-funcional foram excluídas do cômputo de orações verbais do corpus. 
Do exame das listas de concordâncias resultou a Tabela 1 (em anexo). Foram encontradas 1711 ocorrências de verbos com função de processo verbal, o que corresponde a 2,85\% em relação ao total de ocorrências (tokens) e a $0,26 \%$ em relação ao total de palavras do corpus.Esse índice é relativamente baixo se considerado o número total de palavras, o que pode representar o perfil mais procedimental do que dialógico da área de Engenharia.

Por outro lado, a observação de 31 verbos com função de processo verbal levantados no corpus (Figura 1) pode mostrar peculiaridades sobre como os pesquisadores da área de Engenharia utilizam o discurso de outrem e fazem referência ao próprio dizer para salientar aspectos do seu trabalho.

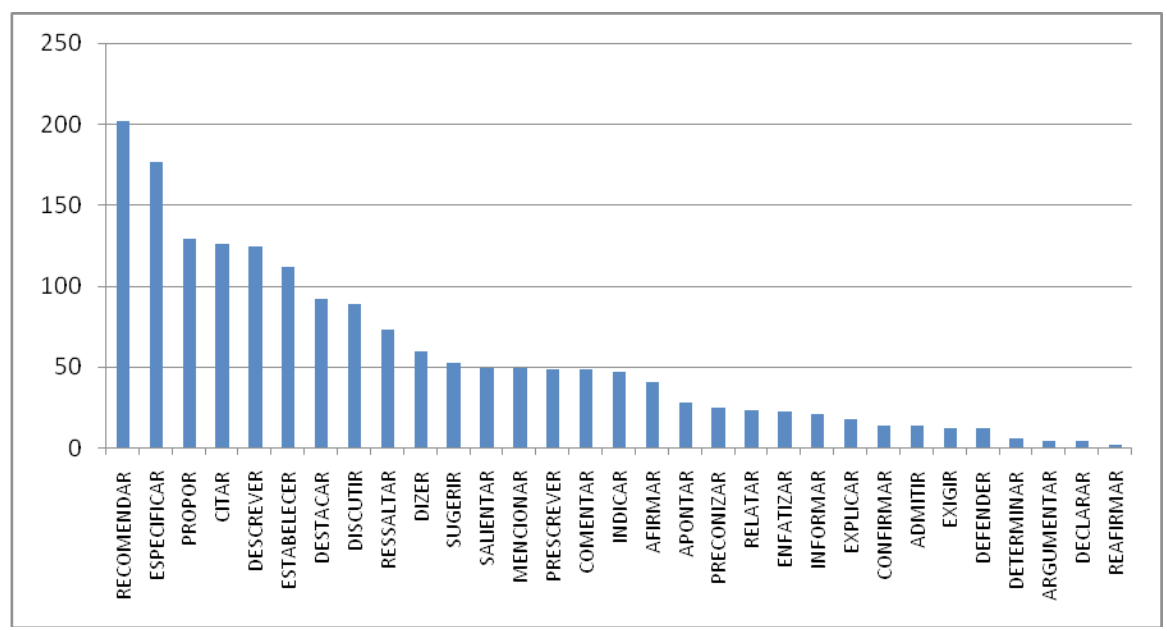

Figura 1: Frequência dos processos verbais.

Os verbos esquadrinhados no corpus realizam processos verbais do tipo semiose, o que confirma o resultado obtido nos estudos de Barbara \& Macêdo (20011) e Vivan (2010) sobre processos verbais em artigos científicos. Entretanto, ao se considerar a área específica em que se produziram os artigos, verifica-se uma variação: os dois processos verbais mais frequentes nos textos da Engenharia Civil em análise são recomendare especificar, diferentemente da frequência constatada por Barbara \& Macêdo (2011) em corpus constituído de artigos científicos de áreas diversas 5 . Nos artigos da

5. Os dois processos mais frequentes no corpus analisado por Barbara \& Macêdo (2011) foram sugerir e afirmar. 
área de Engenharia Civil, o processo afirmar é um dos menos frequentes $(2,3 \%)$, vindo depois de sugerir (3\%). O resultado também difere do encontrado por Vivan (2010) em artigos da área de Linguística Aplicada, em que predominou o processo dizer. Nos textos da Engenharia Civil em análise, entretanto, dizer é o décimo processo na lista de frequências $(3,4 \%)$.

O processo mais frequente no corpus - recomendar $(11,6 \%)$ - enquadra-se no subtipo comando, uma vez que projeta propostas, nos termos de Halliday \& Matthiessen (2004), como nos seguintes exemplos:

(4) Para monitorar a progressão do quadro fissuratório, Klein \& Silva Filho(2009) recomendam que se utilizem os procedimentos descritos a seguir. [File 32]

(5) Os fabricantes de revestimento, frequentemente, recomendam camadas de no máximo $60 \mathrm{~cm}$ de concreto, com o vibrador inserido verticalmente a espaçamentos uniformes, penetrando pelo menos $150 \mathrm{~mm}$ na camada anterior. [File 51]

(6) O ensaio para determinação da evolução das resistências a baixas idades pelo penetrômetro Hilty é recomendado pelo Austrian Concrete Society no seu Guideline on Shotcrete (1990). [File 38]

(7) As ABNT NBR 6118:2007 e ABNT NBR 7680:2007 e as normas internacionais citadas são unânimes em recomendar que se efetue a amostragem de testemunhos extraídos de concreto somente de regiões sãs e íntegras, (...). [File 32]

(8) Para a altura das caixas, recomenda-se que seja determinada de modo a não exceder $50 \mathrm{~kg}$. [File 15]

A função de Dizente, quando explicitada nesse tipo de oração verbal, é desempenhada por terceiros, representados por outros pesquisadores (em 4) ou por referências metonímicas, como categorias funcionais (em 5), instituições (em 6) ou documentos que registram normas técnicas (em 7). Muitas vezes, a função de Dizente não é desempenhada por nenhum elemento da estrutura léxico-gramatical, mas, no contexto situacional em que o texto se insere, pode ser desempenhada pelo próprio autor do artigo, como ocorre em (8).

Além de recomendar, outros verbos presentes no corpus realizam processos verbais de semiose do tipo comando, quais sejam: especificar $(10,2 \%)$, estabelecer (6,5\%), prescrever (2,8\%), preconizar (1,4\%), exigir $(0,8 \%)$ e determinar $(0,4 \%)$, exemplificados a seguir. 
(9) A ABNT NBR 6118:2007 especifica que o cobrimento mínimo deve variar entre $25 \mathrm{~mm}$ e $50 \mathrm{~mm}$ para pilares e vigas de concreto armado, dependendo das condições de exposição. [File 22]

(10) A mesma norma estabelece que o tempo mínimo de mistura somente poderá ser diminuído mediante comprovação da uniformidade da mistura (...) [File 15]

(11) A ASTM C295-08 e a CSA A23.2-15 a também prescrevem a análise petrográfica. [File 27]

(12) Para se ter ideia de prazos, a ABNT NBR 15575:2010 preconiza, de forma pioneira no país, períodos de tempo em que a construção deve atender ao desempenho mínimo para o usuário (vida útil de projeto, com manutenção preventiva e corretiva) (...). [File 36]

(13) A norma também exige que o ensaio de ruptura seja conduzido até a desagregação total e que seja registrada, no relatório de ensaio,a forma de ruptura dos testemunhos extraídos (...). [File 32]

(14) A ABNT NBR 14931:2004 determina que o prazo para retirada do escoramento deve ser função da resistência e do módulo de elasticidade do concreto.(...) [File 31]

Somadas, as ocorrências de processos verbais de semiose de comando totalizam 21,7\%. Esse índice relativamente alto de processos verbais de comando, se comparado ao de processos do tipo indicação predominantes nos corpora analisados nos estudos prévios referidos anteriormente, pode estar relacionado ao perfil do profissional da área. Ao engenheiro civil ou engenheiro de fortificação,segundo a Resolução n ${ }^{\circ} 218$ de 29/06/73 do CONFEA (Conselho Federal de Engenharia, Arquitetura e Agronomia) compete atividades referentes a edificações, estradas, pistas de rolamentos e aeroportos; sistema de transportes, de abastecimento de água e de saneamento, dentre outras. Para isso, deve exigir que os materiais usados estejam em conformidade com as normas técnicas de segurança, qualidade, preservação ambiental e produtividade em vigor. Nesse contexto, justificase a alta frequência do uso, por exemplo, do processo recomendar em seu discurso, uma vez que as ações executadas em seu campo de atuação são regidas por normas técnicas, as quais“ditam” os procedimentos que podem ser realizados e as circunstâncias de execução. 
Além disso, é função do engenheiro elaborar normas e documentação técnica, procedimentos e especificações técnicas, normas de avaliação de desempenho técnico e operacional, normas de ensaio de campo e de laboratório, dentre outras atividades (CONFEA, 1973). Com isso, justifica-se o processo especificar ser o segundo mais frequente nos textos científicos em análise.

Como resultados de pesquisas científicas fazem evoluir as técnicas e, por conseguinte, fornecem subsídios para a elaboração e atualização das normas de engenharia, além da voz de pesquisadores que têm seus achados publicados (o que é típico no discurso científico de várias áreas), aparecem normas técnicas como uma voz de comando.

Com relação às formas linguísticas, os dados quantitativos evidenciaram a predominância de uso dos verbos na $3^{\text {a }}$ pessoa do presente do indicativo (14formas linguísticas e 545 ocorrências) e no particípio (13 formas linguísticas e 894 ocorrências). Esse resultado é semelhante ao encontrado por Barbara \& Macêdo (2011) a partir da análise de artigos científicos da base de dados Scielo, em que predominaram formas linguísticas em $3^{\text {a }}$ pessoa do presente e do pretérito, indicando o caráter impessoal do artigo científico. A ausência de formas em $1^{\mathrm{a}}$ pessoa parece indicar que, assim como a grande maioria dos cientistas, os engenheiros/pesquisadores que produziram os textos em análise optaram por não usar itens léxico-gramaticais que evidenciam a inserção explícita da voz autoral no discurso.

$\mathrm{O}$ uso do presente do indicativo possibilita que um evento discursivo já realizado seja trazido para a instância da enunciação, "presentificando" o que poderia ser percebido como passado na perspectiva do leitor. Isso produz um efeito de permanência do conteúdo do dizer no momento da leitura, como se verifica nestes exemplos:

(15) A ASTM C979:2010 recomenda que a dosagem de pigmento não deve exceder os $10 \%$ em relação à massa de material cimentício. [File 45]

(16) Na falta desses ensaios, a ABNT NBR 9062:2006, no item9.2.1.1.2, estabelece que, desde que seja utilizado concreto com $\mathrm{fck} \geq 40 \mathrm{Mpae}$ relação água/cimento $\leq$ 0,45 , os cobrimentos podem ser reduzidos em mais $5 \mathrm{~mm}$ em relação ao estabelecido no item 9.2.1.1.1 (...) [File 43]

(17) Morgan (1990) cita que a graduação 2 tem sido a mais utilizada e que a graduação 3 é recomendável para seções espessas onde a direção de projeção é predominantemente para baixo.. [File 38]. 
(18) Neville (2003) diz que a água é tratada como no conto de Cinderela: tem sido objeto de poucos estudos e, praticamente, nenhum deles é recente. [File 9]

Ao projetarem Relatos de propostas (em 15 e 16) e de proposições (em 17 e 18), os verbos no presente do indicativo representam a continuação da validade dos conteúdos enunciados em momentos passados, haja vista a referência ao ano de publicação das fontes (2010, 2006, 1990 e 2003). Isso representa os discursos alheios, de certa maneira, como fontes atualizadas de referência, não ultrapassadas e, por conseguinte, válidas no meio científico.

Embora pouco frequentes no corpus, as formas do pretérito merecem uma análise aqui, uma vez que seu uso parece acarretar um efeito inverso ao produzido pelas formas do presente no contexto em questão. Entre as formas verbais do pretérito encontradas no corpus, as mais frequentes são propôs/propuseram e sugeriu, exemplificadas em (19) e (20).

(19) Leite (2001) propôs um método simples para a realização do ensaio de absorção de água ao longo do tempo, através do monitoramento da massa submersa em diferentes intervalos de tempo. A presença de ar incorporado pode gerar erros experimentais porque aumenta o volume do agregado. [File 47]

(20) Lyse sugeriu ainda empregar a Lei de Abrams com relação água/cimento em massa e não em volume, como originalmente proposto por Abrams. (...) Apesar de lógica e de impor-se à razão como uma verdade intuitiva, esses métodos baseados na granulometria descontínua não se generalizaram devido à dificuldade de obter, prática e economicamente, agregados com grãos uniformes que obedeçam a uma dada relação geométrica, variável de uma a outra situação. [File 12]

Verificando-se o co-texto, note-se que as orações verbais com formas do passado são seguidas por outras orações que contêm itens lexicais que promovem uma avaliação negativa, como "erros" em (19) e "não se generalizaram" em (20). Por extensão, o conteúdo do dizer - seja a Verbiagem em (19), seja o Relato em (20) - é representado como uma proposta desatualizada, que não atende plenamente às demandas contemporâneas no campo de aplicação. Assim, formas do pretérito que projetam propostas, especialmente, podem ser usadas, no discurso científico, para contrapor discursos ou representar como pouco válido um discurso anteriormente divulgado na área. 
O emprego deformas no particípio, por possibilitarem tanto a explicitação como o apagamento do Dizente, relaciona-se com questões de progressão temática do texto e de autoria, como se verifica nos exemplos a seguir:

(21) A maioria das metodologias utilizadas para a avaliação da permeabilidade ao ar em concretos não é adequada para a avaliação do desempenho de películas (....). Um método considerado adequado é proposto por Torrent (1991) para estruturas de concreto (...). [File 34]

(22) Os mecanismos de ação dos agentes que concorrem para a formação da vários tipos de problemas patológicos foram discutidos nos Capítulos 19 a 30. Nesta seção são descritas as manifestações patológicas mais comuns, seus sintomas, origens e características. [File 31]

(23) O uso de ácido muriático, nesse caso, não é recomendado, pois pode alterar a coloração final, causando manchamentos e diferenças de tonalidades (JANCY, 2008). [File 45]

Em (21), o emprego do particípio em estrutura passiva possibilita colocar o sujeito da oração ("Um método considerado adequado") em posição temática. Essa organização da mensagem mantém o tema ("metodologias utilizadas para avaliação da permeabilidade ao ar em concretos") apresentado na oração anterior. Ao mesmo tema novas informações são relacionadas na sequência de cada oração. Se optasse por outra forma linguística, como o presente do indicativo, por exemplo, o sujeito da oração teria de ser "Torrent (1991)", e posições temáticas alternativas poderiam ser escolhidas. No entanto, a organização temática escolhida em (21) mantém mais claramente a relação dado-novo e contribui para o que se costuma chamar de "texto fluente".

Em (22) e (23), verifica-se outra finalidade das formas de particípio em processos verbais. O apagamento do Dizente para discutidos, descrita se recomendado sinaliza o encobrimento do falante. Em (22), a ausência de qualquer menção ao Dizente no co-texto permite inferir-se que essa função é preenchida pelo próprio autor do artigo. Já em (23), a função de Dizente poderia ser desempenhada pela fonte bibliográfica, indicada entre parênteses, ao final do período, por meio da referência ao sobrenome e ao ano de publicação. Esse modo de referência à fonte torna pouco precisa o que da proposição (se uma parte ou toda ela) é de responsabilidade do autor mencionado. 
Portanto, ao lado das formas em terceira pessoa (incluindo estruturas passivas sintéticas, como "recomenda-se", "propõe-se", "discute-se"), o particípio pode ser considerado mais uma alternativa para impessoalizar o discurso no artigo científico. Provavelmente em função desse propósito, o número de formas do particípio seja tão próximo ao número de formas em $3^{\mathrm{a}}$ pessoa do presente no corpus ( 13 e 14 formas, respectivamente).

\section{CONSIDERAÇÕES FINAIS}

Tendo utilizado procedimentos teórico-metodológicos de análise pertinentes ao projeto SAL, este trabalho buscou verificar quais formas linguísticas realizam processos verbais, com que frequência são usados e que significados apresentam em textos reunidos numa coletânea de trabalhos científicos publicada por um dos órgãos representativos da área de Engenharia Civil no Brasil.

Os resultados apontam o predomínio de processos verbais de semiose nos textos científicos, confirmando os achados em pesquisas prévias (Barbara \& Macêdo, 2011; Vivan, 2010).Assim, fica evidenciada uma característica comum aos discursos de várias ciências: a referência a representações atribuídas a vozes externas, principalmente de pesquisadores que publicaram seus achados, como fontes de proposições e propostas de alguma maneira relevantes à construção do trabalho científico.

Por outro lado, os processos verbais mais frequentes no corpus- recomendar e especificar - funcionam como processos de semiose do tipo comando. Relacionados a atividades que envolvem a atuação profissional na área de Engenharia Civil, esses verbos, somados a outros menos frequentes (estabelecer, prescrever, preconizar, exigir e determinar), sinalizam uma característica do discurso dessa ciência específica: a presença de normas técnicas, muitas vezes na função de Dizente, como uma voz de comando no discurso.

Com relação às formas linguísticas, predominaram verbos na $3^{\mathrm{a}}$ pessoa do presente do indicativo e no particípio. O uso do presente do indicativo produz efeito de permanência do conteúdo do dizer no momento da leitura, contribuindo para representar os discursos alheios como fontes atualizadas de referência e válidas no meio científico.Ao contrário, para enfraquecer a validade de um discurso anteriormente divulgado na área ou contrapor 
resultados de pesquisa, são usadas formas do pretérito. A forma de particípio em estrutura passiva contribui na organização temática do texto e facilita o apagamento do Dizente. Dessa forma, apresenta-se como uma alternativa para encobrir a voz autoral e impessoalizar o discurso.

Outros aspectos das orações verbais em textos científicos da área de Engenharia Civil ainda estão sendo investigados, como a frequência e os significados das circunstâncias de ângulo, de Verbiagens, Citações e Relatos. Também serão analisados com mais detalhe os outros tipos de processos de semiose (os neutros e os de indicação), a fim de esquadrinhar seus significados no discurso científico da área específica em estudo, em continuidade à pesquisa sobre o uso de orações verbais no contexto científico, conforme prevê o projeto SAL.

Recebido em outubro de 2011 Aprovado em dezembro de 2011 E-mail: crisfuzer@yahoo.com.br

\section{ReFERÊNCIAS BibliográfICAS}

Almeida, G. B.; Correia, M. 2008. Terminologia e corpus: relações, métodos e recursos. In: Tagnin, S. e. O.; Vale, O. A. (Org.). Avanços da Linguística de Corpus no Brasil. São Paulo: Humanitas. p. 67-94.

Barbara, L.; Macedo, C. M. M. de. 2011. Processos verbais em artigos acadêmicos: padrões de realização da mensagem. In: BARBARA, L.; Moyano, E. Textos em linguagem acadêmica: explorações sistêmicofuncionais em espanhol e português. Campinas, SP: Mercado das Letras.

Cabral, S. R. S.; Barbara, L. Processos verbais no discurso jornalístico: frequência e organização da mensagem. (no prelo).

Conselho Federal de Engenharia, Arquitetura e Agronomia. Resolução $n^{0} 218$ de 29 de junho de 1973. Rio de Janeiro, 1973. Disponível em: http://normativos.confea.org.br/downloads/0218-73.pdf. Acesso em: 30 jan. 2012.

Fuzer, C.; Barros, N.C.A. 2010. Ações verbais em textos jurídicos. Nonada, n. 14, p. $83-97$.

Halliday, M. A. K. 1994. An introduction to functional grammar. 2. ed. London: Arnold. 
Halliday, M. A. K.; Matthiessen, C. M. I. M. 2004. An introduction to functional grammar. 3. ed. London: Arnold.

Isaia, G. C. 2011. Concreto: ciência e tecnologia. v. 1 e 2. São Paulo: IBRACON.

. 2007. Concreto: ensino, pesquisa e realizações. Apresentação. v. 1.São Paulo: IBRACON.

Instituto Brasileiro do Concreto. Institucional. Disponível em: http:// www.ibracon.org.br/. Acesso em: 30 jan. 2012.

KurTz, M.S.S.C. 2011. A toga pela mídia: representações da credibilidade do judiciário em notícias online. Santa Maria: UFSM. 178 fls. Tese (Doutorado em Letras), Universidade Federal de Santa Maria, Santa Maria.

Martin, J. R.; White, P. 2005. The language of evaluation: appraisal in English. New York: Palgrave.

Matthiessen, C.; Teruya, K.; Barbara, L. 2008. Systemics Across Languages - Research network. São Paulo: Pontifícia Universidade Católica de São Paulo.

Ramos, M. O. M. 2010. A nominalização de processos verbais: perspectiva sistêmico-funcional da produção textual em contextos escolares. Pontifícia Universidade Católica do Rio de Janeiro. Dissertação de Mestrado. Rio de Janeiro: PUCRJ.

Sardinha, T. B. 2004. Linguística de Corpus. Barureri, SP: Manole.

SiLva, T. S. 2012. Irenes: representações sobre homossexuais idosos no contexto midiático sob a perspectiva sistêmico-funcional.Santa Maria: UFSM. 222 fl. Dissertação (Mestrado em Letras), Programa de PósGraduação em Letras, Universidade Federal de Santa Maria, Santa Maria.

Scotт, M. Word Smith Tools. Oxford: Oxford University Press, 2008.

VIVAN, E.G.S. 2010. Principais usos de processos verbais e metáforas interpessoais em artigos de Linguística Aplicada. São Paulo: PUCSP, 208 fl. Tese (Doutorado em Linguística Aplicada e Estudos da Linguagem), Pontifícia Universidade Católica de São Paulo, São Paulo. 


\section{ANEXO}

Tabela 1: Frequência de verbos que desempenham a função de processo verbal

\begin{tabular}{|c|c|c|c|c|c|c|c|}
\hline \multirow[b]{2}{*}{ Processos verbais } & \multicolumn{5}{|c|}{ Formas linguísticas } & \multirow[b]{2}{*}{ Ocor. } & \multirow[b]{2}{*}{$\%$} \\
\hline & $\begin{array}{c}\text { Pres. } \\
3^{\text {a }} \text { pess. }\end{array}$ & $\begin{array}{c}\text { Pret. } \\
3^{\circ} \text { pess. }\end{array}$ & Partic. & Inf. & Ger. & & \\
\hline RECOMENDAR & 97 & 0 & 99 & 2 & 4 & 202 & 11,6 \\
\hline ESPECIFICAR & 31 & 3 & 130 & 9 & 4 & 177 & 10,2 \\
\hline PROPOR & 11 & 26 & 86 & 5 & 1 & 129 & 7,4 \\
\hline CITAR & 22 & 0 & 78 & 25 & 1 & 126 & 7,3 \\
\hline DESCREVER & 20 & 1 & 133 & 1 & 2 & 125 & 7,2 \\
\hline ESTABELECER & 60 & 2 & 40 & 0 & 11 & 112 & 6,5 \\
\hline DESTACAR & 45 & 0 & 20 & 23 & 4 & 92 & 5,3 \\
\hline DISCUTIR & 11 & 3 & 69 & 6 & 0 & 89 & 5,1 \\
\hline RESSALTAR & 27 & 0 & 8 & 36 & 2 & 73 & 4,2 \\
\hline DIZER & 10 & 2 & 7 & 40 & 1 & 60 & 3,4 \\
\hline SUGERIR & 21 & 4 & 22 & 3 & 3 & 53 & 3 \\
\hline SALIENTAR & 15 & 0 & 2 & 29 & 4 & 50 & 2,9 \\
\hline MENCIONAR & 4 & 0 & 41 & 5 & 0 & 50 & 2,9 \\
\hline PRESCREVER & 23 & 0 & 23 & 3 & 0 & 49 & 2,8 \\
\hline COMENTAR & 21 & 0 & 27 & 0 & 1 & 49 & 2,8 \\
\hline INDICAR & 24 & 0 & 20 & 2 & 1 & 47 & 2,7 \\
\hline AFIRMAR & 11 & 1 & 0 & 23 & 0 & 41 & 2,3 \\
\hline APONTAR & 13 & 3 & 11 & 1 & 0 & 28 & 1,6 \\
\hline PRECONIZAR & 5 & 1 & 19 & 0 & 0 & 25 & 1,4 \\
\hline RELATAR & 11 & 1 & 18 & 2 & 2 & 24 & 1,4 \\
\hline ENFATIZAR & 8 & 0 & 6 & 8 & 1 & 23 & 1,3 \\
\hline INFORMAR & 6 & 0 & 8 & 7 & 0 & 21 & 1,2 \\
\hline EXPLICAR & 8 & 0 & 7 & 3 & 0 & 18 & 1,1 \\
\hline CONFIRMAR & 8 & 0 & 5 & 1 & 0 & 14 & 0,8 \\
\hline ADMITIR & 8 & 3 & 3 & 0 & 0 & 14 & 0,8 \\
\hline EXIGIR & 3 & 0 & 10 & 0 & 0 & 13 & 0,8 \\
\hline DEFENDER & 8 & 2 & 1 & 1 & 1 & 13 & 0,8 \\
\hline DETERMINAR & 5 & 0 & 0 & 1 & 0 & 6 & 0,4 \\
\hline ARGUMENTAR & 5 & 0 & 0 & 0 & 0 & 5 & 0,3 \\
\hline DECLARAR & 4 & 1 & 0 & 0 & 0 & 5 & 0,3 \\
\hline REAFIRMAR & 1 & 0 & 1 & 0 & 0 & 2 & 0,1 \\
\hline TOTAIS & 545 & 53 & 893 & 236 & 43 & 1733 & $100 \%$ \\
\hline
\end{tabular}

